\title{
Control yourself or just eat what you like? Weight gain over a year is predicted by an interactive effect of response inhibition and implicit preference for snack foods
}

Citation for published version (APA):

Nederkoorn, C., Houben, K. M. P. I., Hofmann, W., Roefs, A. J., \& Jansen, A. T. M. (2010). Control yourself or just eat what you like? Weight gain over a year is predicted by an interactive effect of response inhibition and implicit preference for snack foods. Health Psychology, 29(4), 389-393.

https://doi.org/10.1037/a0019921

Document status and date:

Published: 01/07/2010

DOI:

10.1037/a0019921

Document Version:

Publisher's PDF, also known as Version of record

Document license:

Taverne

Please check the document version of this publication:

- A submitted manuscript is the version of the article upon submission and before peer-review. There can be important differences between the submitted version and the official published version of record. People interested in the research are advised to contact the author for the final version of the publication, or visit the DOI to the publisher's website.

- The final author version and the galley proof are versions of the publication after peer review.

- The final published version features the final layout of the paper including the volume, issue and page numbers.

Link to publication

\footnotetext{
General rights rights.

- You may freely distribute the URL identifying the publication in the public portal. please follow below link for the End User Agreement:

www.umlib.nl/taverne-license

Take down policy

If you believe that this document breaches copyright please contact us at:

repository@maastrichtuniversity.nl

providing details and we will investigate your claim.
}

Copyright and moral rights for the publications made accessible in the public portal are retained by the authors and/or other copyright owners and it is a condition of accessing publications that users recognise and abide by the legal requirements associated with these

- Users may download and print one copy of any publication from the public portal for the purpose of private study or research.

- You may not further distribute the material or use it for any profit-making activity or commercial gain

If the publication is distributed under the terms of Article 25fa of the Dutch Copyright Act, indicated by the "Taverne" license above,

Download date: 26 Apr. 2023 


\title{
Control Yourself or Just Eat What You Like? Weight Gain Over a Year Is Predicted by an Interactive Effect of Response Inhibition and Implicit Preference for Snack Foods
}

\author{
Chantal Nederkoorn and Katrijn Houben \\ Maastricht University
}

\author{
Wilhelm Hofmann \\ University of Würzburg and University of Amsterdam
}

\author{
Anne Roefs and Anita Jansen \\ Maastricht University
}

\begin{abstract}
Objective: Previous research showed a strong relation between response inhibition, overeating and overweight. It was shown that people with ineffective response inhibition are more susceptible to the temptations of palatable food, eat more and are more often overweight or obese. In addition the results of several studies suggest that what needs to be inhibited may be an affect-driven motivation for food. In the present longitudinal study, we therefore investigated the interplay of response inhibition and implicit preferences for snack foods in predicting weight gain. Design: In a sample of predominantly normal weight undergraduate female students, implicit preference for food, response inhibition, and body mass index (BMI) were measured. After 1 year, BMI was measured again. Main Outcome Measures: Weight gain of the participants over a 1-year period. Results and Conclusions: The results strongly confirmed our expectations: participants with strong implicit preferences for snack foods and low inhibitory capacity gained the most weight. These findings imply that ineffective response inhibition may render people vulnerable to excessive or impulsive behavior in general, but that the manifestation thereof is determined by domain-specific preferences or needs.
\end{abstract}

Keywords: weight gain, impulsivity, implicit preferences, obesity, self-control

The excess of high caloric, tasty and cheap food has caused a major change in the average posture of people in Western societies in the last decades. Not only the average body mass index (BMI), but also the variation in BMI increased enormously (Wang \& Beydoun, 2007). A factor that is related to the variation in BMI is response inhibition. Response inhibition is an executive function, which is thought to be at the heart of impulsive behavior (Barkley, 1997). It is needed to overrule impulsive or habitual reactions to approach stimuli so that behavior can be regulated in accordance with one's long-term goals and standards (Logan \& Cowan, 1984). Obese adults and children have repeatedly been found to have less effective response inhibition than lean controls (Nederkoorn, Braet, Van Eijs, Tanghe \& Jansen, 2006; Nederkoorn, Guerrieri, Havermans, Roefs \& Jansen, 2009; Verbeken, Braet, Claus, Nederkoorn \& Oosterlaan, 2009).

The proposed explanation for the relation between obesity and ineffective response inhibition is that people with less self-control are more vulnerable to the temptations of tasty high caloric food, which is almost omnipresent in the current Western societies, and

Chantal Nederkoorn, Katrijn Houben, Anne Roefs, and Anita Jansen, Department of Clinical Psychological Science, Maastricht University; and Wilhelm Hofmann, Department of Psychology, University of Würzburg and Department of Developmental Psychology, University of Amsterdam.

Correspondence concerning this article should be addressed to Chantal Nederkoorn, Maastricht University, Faculty of Psychology and Neuroscience, P.O. Box 616, 6200 MD Maastricht, the Netherlands. E-mail: c.nederkoorn@maastrichtuniversity.nl consequently eat more (Appelhans, 2009; Nederkoorn, Smulders et al., 2006; Nederkoorn, Jansen, Mulkens \& Jansen, 2007). Repeated overeating in turn can lead to overweight and obesity. Multiple studies support this proposed explanation. First, participants with less effective response inhibition were found to eat more during a taste test than participants with effective response inhibition (Guerrieri et al., 2007). Second, experimentally inducing a temporary state of impulsivity by manipulating response inhibition led to increased food intake in nondieting participants (Guerrieri, Nederkoorn, Schrooten, Martijn \& Jansen, 2009). Also the use of alcohol, which causes a decreased capability to inhibit responses (Fillmore, Ostling, Martin \& Kelly, 2009) increases food intake (Caton, Ball, Ahern \& Hetherington, 2004). These experimental studies inform us about the direction of the relation between response inhibition and overeating: ineffective response inhibition causes overeating. One would therefore expect that ineffective response inhibition is also causally related to actual weight gain. Although the effect of response inhibition on prospective weight gain is never tested, it has indeed been shown that ineffective response inhibition predicted less weight loss in obese children in treatment (Nederkoorn et al., 2007).

Recent findings however suggest that the effect of response inhibition on food intake may be more complex. In two studies (Nederkoorn et al., 2009), it was found that only participants with ineffective response inhibition who were feeling moderately hungry at that moment ate more during a taste test (Study 1), or bought more snack food items in a virtual supermarket (Study 2). Participants with ineffective response inhibition who were feeling sated 
did not consume more food than participants with effective response inhibition. In previous studies on the effect of response inhibition on eating behavior, participants were always asked to refrain from eating for at least 2 hours (Guerrieri et al., 2007; 2009), making them moderately hungry. Hunger motivates food seeking behavior and food consumption (Raynor \& Epstein, 2003), makes food more rewarding (Siep et al., 2009) and promotes a positive automatic association with food (Stafford \& Scheffler, 2008). These initial findings suggests that it may be affect-driven motivation to eat that needs to be inhibited in the service of overarching goals, like to control one's weight. Besides hunger, hedonic aspects like taste, pleasure and reward are involved in the motivation to eat (Appelhans, 2009). According to dual system models (Strack \& Deutsch, 2004) automatic, affective reactions toward tasty food influence the motivational drive to consume that food (see also Hofmann, Friese, \& Roefs, 2009). This motivational drive can, however, be overruled by a higher order inhibitory control system. The inhibitory control system makes it possible that more deliberate long term goals prevail, which in the case of consummatory behavior often reflect personally endorsed health concerns or social norms. When control resources are depleted or inadequate, the motivational drive will be more dominant in guiding behavior. In several laboratory studies, it was found that when self-control was situationally reduced, consumption was predicted by implicit measures of food preferences, as measured with an Implicit Association Task (IAT). When control resources were not depleted, however, this relationship was absent (Friese, Hofmann \& Wänke, 2008; Hofmann, Rauch \& Gawronski, 2007; Hofmann $\&$ Friese, 2008). It appeared essential to measure preference for food in an implicit way: explicit self-report of these preferences was no related to food intake in the depleted states. In the IAT, responses are assumed to be relatively automatic, because stimuli are presented in quick succession and participants are urged to respond quickly, leaving insufficient time for controlled processing. Implicit measures of preferences might therefore be less influenced by demand characteristics and a better measure of the automatic affective value of food than explicit measures (Strack \& Deutsch, 2004).

Not only state differences in control resources appeared to moderate the effect of implicit preferences for food on actual intake, also stable individual differences did. In people who are less effective in cognitive control, implicit preferences for a specific food predicted food intake much more strongly than in participants with more effective cognitive control functions (Hofmann, 2009).

Taken together, these experimental studies suggest that response inhibition alone might not be a strong predictor of weight gain. Neither may stronger preferences per se translate into increased snack consumption. The stronger people's preference or motivation for snack food, the more inhibitory capacity they may need to recruit to override impulsive action tendencies to consume snack foods. Put differently, individual differences in inhibitory control may be most decisive for determining self-regulatory success or failure for people with high (rather than low) implicit preferences for snack food. Without strong automatic preferences for snack foods, a lack of response inhibition should not lead to overeating.

The previous studies are limited to a single occasion of food intake in the lab, in which the effects of implicit preferences and inhibition can be studied in isolation. A longitudinal study on weight gain is needed to test the validity in the real world. In the present study, weight gain over 1 year in undergraduate female students was tested.
It was predicted that response inhibition and implicit preference for snack foods would interact in the prediction of weight gain: Participants without effective response inhibition and a strong implicit preference for snack foods were expected to gain the most weight.

\section{Method}

\section{Participants}

Maastricht University female undergraduate students were recruited by advertisements at the university building. Exclusion criteria were serious health problems, pregnancy, and obesity (defined as BMI >30). A total of 74 students participated at $\mathrm{T}=1$ (mean age 19.7 [ $S D$ 1.9]; mean BMI $=21.5[S D=2.3]$ ). One participant was excluded from the analyses because her score on the Single Category IAT (SC-IAT) task (explained below) exceeded three $S D$ s from the mean. Of the remaining 73 students, 51 participated at $T=2$. The missing 22 students discontinued their study program, could not be reached or did not want to participate. The participants who dropped out did not differ from the included participants on age, $t(71)=1.3$, $p=.18$, BMI, $t(71)=0.5, p=.62$, response inhibition (stop signal reaction time; SSRT), $t(71)=0.3, p=.74$, or preference for foods $(\mathrm{SC}-\mathrm{IAT}), t(71)=1,4, p=.16$.

The completers had a mean age of $19.5(S D=2.2)$, mean BMI of $21.4(S D=2.2)$, mean length of $1.71 \mathrm{~m}(S D=.07)$ and mean weight of $63 \mathrm{~kg}(S D=8.4)$. Two participants were slightly overweight (BMI of respectively 26.1 and 26.4).

\section{Measures}

Weight change. Height and body weight were measured while the participant was dressed in her underwear. BMI was and weight change was calculated.

Response inhibition. The stop signal task (Logan, Schachar \& Tannock, 1997) was used to measure response inhibition. The stop signal task is a choice reaction time paradigm in which the participants must respond as fast as possible to a visual go-signal (an $\mathrm{X}$ or an $\mathrm{O}$ ), unless an auditory stop signal is presented (through headphones) in which case the response must be inhibited (25\% of the trials). Initially, the stop signal delay was set at $250 \mathrm{~ms}$ after the presentation of the go signal and then adjusted dynamically depending on the participant's responses, hereby enabling the participant to stop on approximately $50 \%$ of the stop trials. The participants completed two practice blocks without stop signals and one with stop signals. Afterward, they completed four test blocks of 128 trials successively. The two variables measured in this task are reaction time (RT) and mean stop delay. The SSRT (measured in $\mathrm{ms}$ ) was calculated by subtracting the stop delay from RT. Higher SSRTs indicate less inhibitory control. Response inhibition, measured with this task, has been shown to be related to impulsivity (Logan et al., 1997) and to discriminate between obese and lean participants (Nederkoorn, Braet et al., 2006). The task has high reliability (Cronbach's alpha $=.87$ ).

Implicit preference for snack food. Preference for snack foods was measured implicitly with a SC-IAT (Karpinski \& Steinman, 2006). The target category was food, and the attribute/ evaluative categories were "I like" and "I don't like." Evaluative stimuli were six positive and six negative pictures from the IAPS (Lang, Bradley \& Cuthbert, 2001; nr. 1300, 1603, 2070, 2550, 
$5480,5623,6550,6570,8200,9220,9340,9600)$. The target stimuli were six food pictures, depicting a bag of crisps, chocolate, chocolate chip cookie, French fries, a hamburger and a pizza. The participant first completed a practice block in which only negative and positive pictures had to be categorized. In the next block, the first combined block (72 trials in a fixed random order) the participant had to respond to the positive category and food with one response key and to the negative category with the other response key. This assignment was changed in the second combined block such that the negative category and food shared a response key. All participants completed the SC-IAT blocks in the same order (Gawronski, 2002). In the first combined block 30 negative pictures, 12 positive pictures and 30 food pictures were presented and in the second combined block 30 positive pictures, 12 negative pictures and 30 food pictures. IAT scores were calculated using the D600-algorithm proposed by Greenwald, Nosek, and Banaji (2003) such that more positive values indicate a more positive reaction to food. The SC-IAT with pictures of M\&M's has been shown to be related to candy intake before (Hofmann et al., 2009). The task has good reliability (corrected split half reliability: $r=.88)$.

\section{Procedure}

The study was approved by the Maastricht University, Faculty of Psychology and Neuroscience Ethical Committee. The participants were tested in groups of one to three people, each seated in a separate cubical. First, they were asked to read and sign the informed consent form. Next, they performed the stop signal task and subsequently the SC-IAT. Afterward, weight and height were measured; participants were thanked for participation and received a small compensation fee (either a course credit or 10 euro). After one year, the participants were contacted again and asked to come to the lab to measure weight and height again.

\section{Statistical Analysis}

A hierarchical linear regression model was used to predict weight change. In the first step, BMI was entered. In the second step, response inhibition and implicit preference for snack foods were entered and in the third step, the interaction term of response inhibition $\times$ implicit preference for snack foods was entered. All variables were centered before entering in the model.

\section{Results}

BMI correlated significant with weight change, no other significant correlations were found (see Table 1). Mean weight gain was $0.4 \mathrm{~kg}(S D=3.2)$. The hierarchical linear regression model is presented in Table 2. BMI was a significant predictor of weight
Table 2

Summary of Hierarchical Regression Analysis for Variables Predicting Weight Change

\begin{tabular}{lcccc}
\hline \multicolumn{1}{c}{ Variable } & B & SE B & B & $p$ \\
\hline Step 1 & & & & \\
$\quad$ BMI & -.53 & .19 & -.37 & .007 \\
Step 2 & & & & \\
$\quad$ BMI & -.51 & .19 & -.36 & .009 \\
Response inhibition & .013 & .01 & .17 & .199 \\
$\quad$ Snack food preference & -1.14 & 1.4 & -.10 & .433 \\
Step 3 & -.49 & .18 & -.34 & .01 \\
$\quad$ BMI & .014 & .01 & .19 & .14 \\
Response inhibition & -1.29 & 1.39 & -.12 & .36 \\
Snack food preference & & & & \\
$\quad$ Response inhibition $\times$ snack & .08 & .04 & .27 & .039 \\
$\quad$ food preference & & & & \\
\hline
\end{tabular}

Note. $R^{2}=.14$ for Step $1(p<.01) ; \Delta R^{2}=.04$ for Step 2 (n.s.); $\Delta R^{2}=$ .073 for Step $3(p<.05)$.

change: participants with a higher BMI lost more weight. Response inhibition and implicit preference for snack foods did not predicted weight change above BMI. It was ost important, however, that response inhibition and implicit preference for snack foods interacted significantly in their effect on weight change, $\beta=$ $.28, \Delta R^{2}=.073, p=.039$. Simple slopes are plotted in Figure 1, which shows that for participants with a low implicit preference for snack food $(-1 S D)$ response inhibition did not significantly influence weight change, $\beta=-.12, t(46)=-.65, p=.52$, but for participants with high implicit preference for snack food (+1 $S D)$ response inhibition had a decisive influence on weight change, $\beta=.48, t(46)=2.5, p=.017$ : Participants with less effective response inhibition gained more weight than participants with more effective response inhibition.

\section{Discussion}

This is the first study in which the effect of response inhibition in interaction with implicit snack food preferences on weight change over time was studied. Results confirmed our hypothesis: Response inhibition and implicit preference for snack foods interacted in their effect on weight change. Participants with less effective response inhibition gained more weight, but only when they also had a strong preference for snack foods as measured with the SC-IAT. For participants with low preference for snack food, response inhibition did not influence weight gain.

We hypothesize that the interactive effect of response inhibition and implicit preferences for snack food on weight gain is mediated by dietary intake, for example, by the actual consumption of the preferred snack foods. To note, we did not measure actual intake

Table 1

Correlations, the Mean (and SD) of the Variables

\begin{tabular}{|c|c|c|c|c|}
\hline & 1 & 2 & 3 & Mean $(S D)$ \\
\hline 1. Weight change & & & & $0.42(3.16) \mathrm{kg}$ \\
\hline 2. BMI & $-.37(p=.007)$ & & & $21.4(2.2)$ \\
\hline 3. Response inhibition & $.20(p=.16)$ & $-.08(p=.56)$ & & $200.2(43.5) \mathrm{ms}$ \\
\hline 4. Implicit preference for snack food & $-.10(p=.51)$ & $-.02(p=.87)$ & $.006(p=.97)$ & $0.47(0.29)$ \\
\hline
\end{tabular}




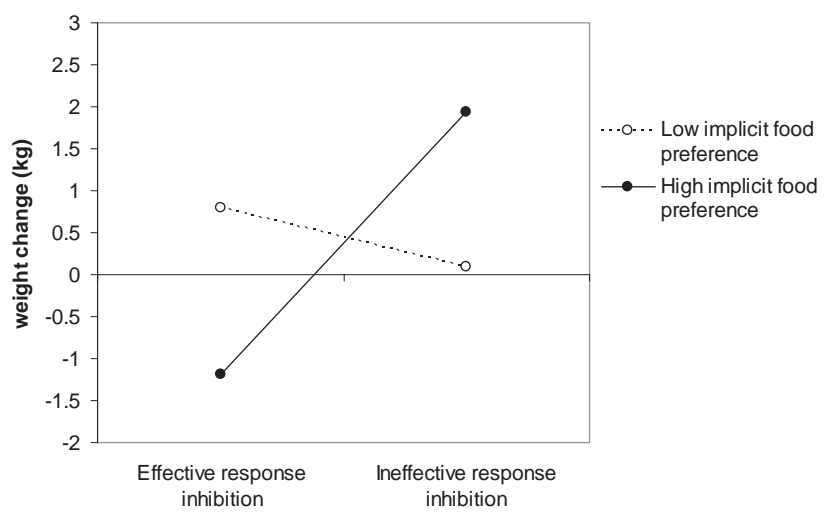

Figure 1. Weight change (in $\mathrm{kg}$ ) as a function of effective and ineffective response inhibition (respectively $1 S D$ below and $1 S D$ above the mean Stop Signal Reaction Time) and low versus high implicit preference for snack food (respectively $1 S D$ below and $1 S D$ above the mean SC-IAT score).

and cannot exclude alternative mediators. In addition, the present study has a small sample size and therefore reduced power to reveal small effects. A study with more participants might show that inhibitory control is also main predictor of weight gain. However, in the present study the strength of the implicit preference for snack foods appeared decisive for the effect of response inhibition on weight gain. This result is consistent with contemporary dual system models (e.g., Strack \& Deutsch, 2004). In short, the automatic system influences the direction and strength of the motivational drive toward stimuli. The control system in contrast determines how well the automatic system is regulated or controlled. In the present study, response inhibition (a measure of the capacity of the deliberative, control system) and implicit preference for snack foods (a measure of the automatic system) were independent from each other, but interacted in their effect on weight gain. This is precisely like the dual system models would predict. The participants with ineffective response inhibition and a relatively lower implicit preference for snack foods might have expressed their lack of self-control in other areas. The model thus can explain that although response inhibition predicts a variety of behaviors, including obesity and overeating (Nederkoorn, Braet et al., 2006), drinking behavior and alcoholism (Nigg et al., 2006), and gambling (Goudriaan, Oosterlaan, de Beurs, \& van den Brink, 2006), the correlations between these behaviors is absent or even negative (Kleiner et al., 2006; Mather, Cox, Enns \& Sareen, 2008). The automatic system determines the direction and strength of desires, the capacity to control yourself determines if you act on them.

It is interesting that participants with strong implicit preferences and effective response inhibition even tended to lose weight over the period of 1 year. The pattern of findings is reminiscent of what Petty and Wegner (1993) termed an overcorrection effect. Perhaps then, strong implicit preferences toward tempting food cues may serve to remind people of the very self-regulatory goals they wish to attain. Given sufficient self-regulatory capacity in the form of behavioral inhibition, people may actually attain their selfregulatory goals.

In the present study, participants who gained weight had a lower initial BMI compared to the participants who lost weight. This finding is in agreement with the literature on this specific group of first year students (Wengreen \& Moncur, 2009). It is not unlikely that physical maturation plays a role in the participants with the lowest BMI, explaining their larger weight gain. In addition, some participants with a higher BMI might have adjusted their lifestyles in order to reduce their BMI as they possibly experience a larger drive for thinness in an environment with predominantly lean people. For many undergraduate students, life changes drastically during their first year at the university, particularly due to leaving parental homes. Independent of initial BMI, participants low in inhibitory control and high in implicit preferences for snack food gained weight. The majority of participants in the present study did not develop overweight and remained of normal weight. However, prolonged weight gain might ultimately result in overweight, suggesting that response inhibition in interaction with implicit preferences for snack food is potentially involved in the development of overweight and obesity. More research is however needed to confirm this. There is already converging evidence that response inhibition is related to obesity and hinders treatment success (e.g., Nederkoorn et al., 2007). This would implicate that research aimed at treatment of obesity could focus at the effectiveness of increasing response inhibition capabilities. Preliminary studies in children with attention deficit hyperactivity disorder show that training working memory, which enhances response inhibition, might have positive effects on reducing impulsive behavior (Klingberg et al., 2005). The effect on eating behavior has not been studied yet, but it appears worthwhile to investigate if training response inhibition might help controlling food intake and maintaining a healthy weight.

In conclusion, the present study shows that specifically participants with less effective response inhibition and a strong implicit preference for snack food gained most weight during a 1-year period. A plausible mechanism is that these people indulge more often in consuming too many calories. Training in response inhibition or lowering the implicit preference for snack food might strengthen their resistance to the daily temptations of palatable food.

\section{References}

Appelhans, B. M. (2009). Neurobehavioral inhibition of reward-driven feeding: Implications for dieting and obesity. Obesity, 17, 640-647.

Barkley, R. A. (1997). Behavioral inhibition, sustained attention, and executive functions: Constructing a unifying theory of ADHD. Psychological Bulletin, 121, 65-94.

Caton, S. J., Ball, M., Ahern, A., \& Hetherington, M. M. (2004). Dosedependent effects of alcohol on appetite and food intake. Physiology and Behavior, 81, 51-58.

Fillmore, M. T., Ostling, E. W., Martin, C. A., \& Kelly, T. H. (2009) Acute effects of alcohol on inhibitory control and information processing in high and low sensation-seekers. Drug and Alcohol Dependence, 100, 91-99.

Friese, M., Hofmann, W., \& Wänke, M. (2008). When impulses take over: Moderated predictive validity of explicit and implicit attitude measures in predicting food choice and consumption behaviour. British Journal of Social Psychology, 47, 397-419.

Gawronski, M. (2002). What does the implicit association test measure? A test of the convergent and discriminant validity of prejudice-related IATs. Experimental Psychology, 49, 171-180.

Goudriaan, A. E., Oosterlaan, J., de Beurs, E., \& van den Brink, W. (2006). Neurocognitive functions in pathological gambling: A comparison with 
alcohol dependence, Tourette syndrome, and normal controls. Addiction, $101,534-547$

Greenwald, A. G., Nosek, B. A., \& Banaji, M. R. (2003). Understanding and using the Implicit Association Test: I. An improved scoring algorithm. Journal of Personality and Social Psychology, 85, 197-216.

Guerrieri, R., Nederkoorn, C., Schrooten, M., Martijn, C., \& Jansen, A. (2009). Inducing impulsivity leads high and low restrained eaters into overeating, whereas current dieters stick to their diet. Appetite, 53, 93-100.

Guerrieri, R., Nederkoorn, C., Stankiewicz, K., Alberts, H., Geschwind, N., Martijn, C., \& Jansen, A. (2007). The influence of trait and induced state impulsivity on food intake in normal-weight healthy women. Appetite, $49,66-73$

Hofmann, W., \& Friese, M. (2008). Impulses got the better of me: Alcohol moderates the influence of implicit attitudes toward food cues on eating behaviour. Journal of Abnormal Psychology, 117, 420-427.

Hofmann, W., Friese, M., \& Roefs, A. (2009). Three ways to resist temptation: The independent contributions of executive attention, inhibitory control and affect regulation to the impulse control of eating behavior. Journal of Experimental Social Psychology, 45, 431-435.

Hofmann, W., Rauch, W., \& Gawronski, B. (2007). And deplete us not into temptation: Automatic attitudes, dietary restraint, and self-regulatory resources as determinants of eating behavior. Journal of Experimental Social Psychology, 43, 497-504.

Karpinski, A., \& Steinman, R. B. (2006). The Single Category Implicit Association Test as a measure of implicit social cognition. Journal of Personality and Social Psychology, 91, 16-32.

Kleiner, K. D., Gold, M. S., Frost-Pineda, K., Lenz-Brunsman, B., Perri, M. G., \& Jacobs, W. S. (2004). Body mass index and alcohol use. Journal of Addictive Diseases, 23, 105-118.

Klingberg, T., Fernell, E., Olesen, P. J., Johnson, M., Gustafsson, P., Dahlström, K., ... Westerberg, H. (2005). Computerized training of working memory in children with ADHD: A randomized, controlled trial. Journal of the American Academy of Child and Adolescent Psychiatry, 44, 177-186.

Lang, P., Bradley, M. M., \& Cuthbert, B. N. (2001). International affective picture system (IAPS): Instruction manual and affective ratings. (Tech. Rep. No. A-5.) The Center for Research in Psychophysiology, University of Florida.

Logan, G. D., \& Cowan, W. B. (1984). On the ability to inhibit thought and action: A theory of an act of control. Psychological Review, 91, 295327.

Logan, G. D., Schachar, R. J., \& Tannock, R. (1997). Impulsivity and inhibitory control. Psychological Science, 8, 60-64.

Mather, A. A., Cox, B. J., Enns, M. W., \& Sareen, J. (2008). Associations of obesity with psychiatric disorders and suicidal behaviors in a nationally representative sample. Journal of Psychosomatic Research, 66, 277-285.

Nederkoorn, C., Braet, C., Van Eijs, Y., Tanghe, A., \& Jansen, A. (2006). Why obese children cannot resist food: The role of impulsivity. Eating Behaviors, 7, 315-322.

Nederkoorn, C., Guerrieri, R., Havermans, R. C., Roefs, A., \& Jansen, A. (2009). The interactive effect of hunger and impulsivity on food intake and purchase in a virtual supermarket. International Journal of Obesity. 33, 905-912.

Nederkoorn, C., Jansen, E., Mulkens, S., \& Jansen, A. (2007). Impulsivity predicts treatment outcome in obese children. Behaviour Research and Therapy, 45, 1071-1075.

Nederkoorn, C., Smulders, F. T. Y., Havermans, R. C., Roefs, A., \& Jansen, A. (2006). Impulsivity in obese women. Appetite, 47, 253-256.

Nigg, J. T., Wong, M. M., Martel, M. M., Jester, J. M., Puttler, L. J., Glass, J. M., ... Zucker, R. A. (2006). Poor response inhibition as a predictor of problem drinking and illicit drug use in adolescents at risk for alcoholism and other substance use disorders. Journal of the American Academy of Child and Adolescent Psychology, 45, 468-475.

Petty, R. E., \& Wegener, D. T. (1993). Flexible correction processes in social judgment: Correcting for context-induced contrast. Journal of Experimental Social Psychology, 29, 137-165.

Raynor, H. A., \& Epstein, L. H. (2003). The relative-reinforcing value of food under differing levels of food deprivation and restriction. Appetite, $40,15-24$

Siep, N., Roefs, A., Roebroeck, A., Havermans, R., Bonte, M. L., \& Jansen, A. (2009). Hunger is the best spice: An fMRI study of the effects of attention, hunger, calorie content on food reward processing in the amygdala and orbitofrontal cortex. Behavioral Brain Research, 198, $149-158$.

Stafford, L. D., \& Scheffler, G. (2008). Hunger inhibits negative associations to food but not auditory biases in attention. Appetite, 51, 731-734.

Strack, F., \& Deutch, R. (2004). Reflective and impulsive determinants of social behavior. Personality and Social Psychology Review, 8, 220-247.

Verbeken, S., Braet, C., Claus, L., Nederkoorn, C., \& Oosterlaan, J. (2009). Childhood obesity and impulsivity: An investigation with performancebased measures. Behavioural Change, 26, 153-167.

Wang, Y., \& Beydoun, M. A. (2007). The obesity epidemic in the United States-gender, age, socieconomic, racial/ethnic, and geographic characteristics: A systematic review and meta-analysis. Epidemiologic Reviews, 29, 6-23.

Wengreen, H. J., \& Moncur, C. (2009). Change in diet, physical activity, and body weight among young-adults during the transition from high school to college. Nutrition Journal, 8, doi:10.1186/1475-2891-8-32 